\title{
1. Introduction: globalising endemic youth unemployment
}

\subsection{THE ENTRENCHMENT OF YOUTH UNEMPLOYMENT}

Unemployment is widely recognised as a major feature of the extreme social and economic inequalities that are characteristic features of the contemporary world order. A great deal of research and thought has been expended in charting how the social organisation of the economy, education, work and welfare have contributed to its production, maintenance and mitigation, and while there is no consensus on this, one thing is clear: involuntary unemployment is devastating and life-changing at any age, but its impacts are particularly adverse for young people. As myriad studies have shown, unemployment indelibly 'scars' the lives of young people and those around them way beyond their immediate lack of income. It adversely affects their health, their transition to social and financial independence, and their prospects of accessing and keeping hold of the quality jobs that are fundamental to socio-economic security and human capability throughout the life-course. At a wider level, youth unemployment (YU) undermines the personal and collective resources invested in education and skills development. At a societal level, sustained rates of high YU challenge liberal notions of inclusive citizenship as a foundation of modern societies and of the social and political order itself - as both liberal and authoritarian democracies have discovered to their cost in recent years.

These are all good reasons to be alarmed about how YU has remained a large-scale, enduring and entrenched feature of the world economy. According to the most authoritative data provided by the International Labour Organization (ILO), over the last twenty years the global rate of YU has remained consistently in the 12-14 per cent range. Absolute annual totals of young unemployed people aged 15-24 have fluctuated between 70 and 80 million (ILO, 2017a). A decade on from the global financial crisis (GFC), which produced a dramatic and immediate spike of 76 million young unemployed people in 2009 followed by a decline to 67 million by 2018, the YU rate was already slowly, steadily increasing again and projected to do so further, even before the onset of the Covid-19 Coronavirus pandemic in 2020. These figures do not include forms of non-participation in the formal labour market which are not counted among the official unemployment figures. These statistics take no account of the more than 700 million young people worldwide who are classified as being 'not in the labour force', irrespective of whether this is by choice and preference or imposed by a range of prevailing adverse socio-economic conditions or hostile circumstances.

The Executive Summary of ILO's most recent annual Global Employment Trends for Youth report (ILO, 2020a: 13) offers a single headline comment that is of direct relevance to the persistent levels of YU in the wake of the GFC: '[y]oung workers continue to face high rates of poverty and are increasingly exposed to non-standard, informal and less secure forms of 
employment'. Unemployment is of course referred to elsewhere in the report but at no point are its extremes mentioned in the Summary. There is no headline that highlights, for example, that the mean YU rate has been above 30 per cent for one year in every two since 1991 (including the last five years) in Northern Africa; or that the average YU rate amongst the world's second poorest group of countries (more than one country in every five) has shown an almost continuous five percentage point rise over three decades (16 per cent in 2019), with no hint of recovery from the GFC. In our view, the ILO currently understates the seriousness of the depth and extent of global YU - even allowing that official ILO data do not take into account hidden and 'invisible' forms of unemployment referred to above.

Five years into the 15-year period of the United Nations' Sustainable Development Goals (SDGs), realising the youth (15-24 age group) employment aspects of Goal 8.5 - 'achieve full and productive employment and decent work for all women and men, including for young people and persons with disabilities, and equal pay for work of equal value' (our emphasis) by 2030 looks a remote prospect, even before the Covid-19 pandemic took hold. In 2019, the $\mathrm{UN}$ reported ambivalent progress on unemployment, in that:

The global unemployment rate has finally recovered from the global economic crisis. In 2018, the global unemployment rate stood at 5.0 per cent - matching pre-crisis levels. Youth were three times more likely to be unemployed than adults. ${ }^{1}$

Goal 8.6 pledges that by 2020 the world will have 'substantially reduce[d] the proportion of youth not in employment, education or training'. Yet, realising this goal for this sub-group of young people still has a long way to go:

In 2018, one fifth of the world's youth were not in education, employment or training, meaning that they were neither gaining professional experience nor acquiring or developing skills .... There is a stark gender difference. Young women were more than twice as likely as young men to be unemployed or outside the labour force and not in education or training. ${ }^{2}$

In all, data of this kind for the period 2000-19 underpin two unprecedented claims that lie at the core of this book. The first is that YU had already become a prevalent social phenomenon by the time of the GFC. At the onset of the GFC in 2008, young people comprised 16 per cent of the world's population and 25 per cent of its working-age population but accounted for 43.7 per cent of the unemployed, meaning that 'almost every other jobless person in the world is between the ages of 15 and 24' (UNDESA, 2007: 238). Prior to the GFC, the rate of young people's participation in the labour market in many countries around the world, not just in the OECD and European Union (EU), had been in a marked and steady decline for many years.

1 Progress of Goal 8 in 2019, https://sustainabledevelopment.un.org/sdg8 (accessed 2 August 2019). See also on the same site: 'The global unemployment rate in 2017 was 5.6 per cent, down from 6.4 per cent in 2000. The decline has slowed since 2009, when it hit 5.9 per cent. Youth are three times more likely to be unemployed than adults, with the global youth unemployment rate at 13 per cent in 2017' (Progress of Goal 8 in 2018). And: 'The global unemployment rate stood at 5.7 per cent in 2016, with women more likely to be unemployed than men across all age groups. Youth were almost three times as likely as adults to be unemployed, with unemployment rates of 12.8 per cent and 4.4 per cent, respectively, in 2016' (Progress of Goal 8 in 2017).

2 Progress of Goal 8 in 2019, https://sustainabledevelopment.un.org/sdg8 (accessed 2 August 2019). 
The second claim is that since the onset of the GFC there is substantial evidence that YU has made a quantum shift to become endemic. We use the adjective 'endemic' deliberately, and we mean it in three senses. One in that, more than ten years on from the GFC, YU is largely sustained at totals at, or close to, the peaks of the early 2010s. Two, it has continued at broadly similar levels long after the end of the 'formal' recessionary conditions after 2008 that characterised the economies of much of the Global North. Three, it has effectively normalised significantly-raised expectations of YU levels across most parts of the world. We return in detail to these observations, but in effect, as this book will argue, there seems to be a degree of medium-term acceptance of levels of YU that greatly exceed those of most of the period since the end of the Second World War.

This book encapsulates these claims in the term endemic youth unemployment (EYU). The new evidence we bring to bear here shows that EYU is a persistent and prevalent feature of contemporary global social organisation. It is a feature of all continents, most regions, and a great many countries, state-types and political-economic and welfare system types. In much of Africa and parts of Asia, Europe and beyond, unemployment has been consistently sustained between 30 per cent and 50 per cent of the youth labour force. EYU is not the prerogative of poorer countries. Fourteen European countries had YU rates above 30 per cent for several years following the GFC, including in some OECD countries where rates exceeded 50 per cent - for up to nine consecutive years in two cases. Modelled rates of YU for most current and recent major conflict and post-conflict zones of the world considerably exceed most of the rates cited above. ${ }^{3}$ Unemployment rates of young women are predominantly higher than those of young men.

The data cited above begin to illustrate our core argument that EYU is a major global issue. They suggest that EYU can be expected to prevail for decades ahead unless major and significant interventions are made in social organisation and political-economic environments, and at levels above those that can be achieved by local interventions and domestic actors alone. Realising the global policy ambition to 'leave no one behind, anywhere' requires a different order of analysis and action than that which has dominated to date. Most academic scholarship on work and welfare landscapes for young people has failed to grasp how transnational structures, processes and sites of capital accumulation, political engagement and types of consciousness bear on the production, maintenance, distribution and mitigation of YU. Indeed, the integration of transnational analytics into social, economic and public policy analysis has not yet reached the study of how young people are positioned and re-positioned in labour and welfare systems, or of how this positioning plays out across a range of development contexts worldwide. The precepts of methodological nationalism and advanced country biases to which studies of young people and social policy have remained unusually susceptible are, we argue, wholly insufficient for recognising and interpreting the emergent normalised levels of YU. The dominance of such precepts invisibilise the links, ties and activities that stretch beyond

\footnotetext{
3 No YU data have been available since 2005 or earlier for other current or recent major conflict zones (Afghanistan, Iraq, Myanmar, Niger, Rwanda, Senegal, Sierra Leone or South Sudan, Syria): ILO WESODATA (https://www.ilo.org/wesodata, accessed 3 August 2020) provides modelled data where national returns of data are not available. Much unemployment is not captured in official rates which take no account of multiple forms of unrecorded unemployment or of casual, informal and insecure employment.
} 
the domestic sphere, and how these refract back into it to restructure economic and social organisation.

There is a pressing need for a transnationalist social policy analytics capable of comprehending how the causes of $\mathrm{YU}$ are rooted in international and not just national social, economic and political structures or in dysfunctional local labour markets, ineffective welfare systems or in unemployed individuals' lack of motivation and skills. This book is born from that imperative. Eschewing facile globalisation narratives that over-simplify the complexities of major social and economic transformations of our time (Yeates, 2001), we elucidate major features of the worldwide, border-spanning 'systemic tendencies' that tangibly condition work and welfare landscapes and the early labour market experiences of young people. Specifically, we elaborate a transnational social policy analytics of YU that is rooted in world economy dynamism and the re-making of welfare systems that together structure global social organisation. We address 'upstream' conditions that give rise to EYU worldwide and the role of institutions of global governance in those processes. Sensitivity to the maximum variety of political-economic and development contexts opens up differences and similarities, divergence and convergence, and, with this, the prospect of deeper, more nuanced insights into the structural causes of YU than most studies of YU to date have offered. Finally, our social policy focus routes attention to labour organisation and economies not as an end in themselves but as means of social participation, inclusion and equality. By invoking a multi-dimensional concept of YU and the necessity of multi-sectoral analysis and action, we propose an alternative to the economic reductionism which accounts for the major share of globalist analyses of YU and labour markets to date.

We make no claim to the novelty of these maximally internationally-extensive global policy 'optics', but it remains rare for them to be combined at once, even in Global Social Policy studies. This book is the first extended study of young people that deploys such optics. Our focus on young people brings specificity and contextualisation into these global analytics, at the same time as these analytics bring a fresh look at the restructuring of youth education, work and welfare landscapes that have been a feature of welfare restructuring internationally. In this, the book charts an incipient and exciting new research terrain. It defines a new global social (policy) field and subjects it to historically grounded, policy-relevant, internationally-oriented critical social analysis that brings transnational structures, processes, institutions and actors to the foreground as major protagonists in the (re)making of YU. The work of demonstrating the centrality of the study of social policy to that of YU, nationally, regionally and globally (and vice-versa), begins in Chapter 2 and continues throughout the book.

The next part of the chapter elaborates on these opening statements and arguments. It discusses our choice of unemployment as a central conceptual framework (Section 1.2), elaborates the concept of EYU (Section 1.3), and explains the analytical value of the prefix 'global' (Section 1.4). It then elaborates the aims, scope and debates structuring the book (Section 1.5), our methods and data (Section 1.6), and our key terms (Section 1.7).

\subsection{UNEMPLOYMENT AS A CENTRAL ORGANISING CONCEPT}

Our choice of unemployment as a central organising category for this global study may be considered peculiar by readers who are well-versed in social policy. Although unemployment 
is the most frequently measured labour market indicator and one of the best available measures of labour under-utilisation, it is also a highly restrictive category that struggles to capture the complexity of relationships to work, employment and joblessness. For example, some official unemployment rates are based on those people who fulfil all the eligibility criteria attached to the receipt of an income support benefit expressly designated as intending to 'compensate' for periods of joblessness as provided for under the terms of the scheme. The strictures of needing to be available for, and actively seeking, work limit receipt of unemployment payments in practice and reduce the number of people officially counted as unemployed. Other measures of unemployment (including some official ones) are based on surveys of whether people have looked for work during a particular period, even if they are not immediately available. This is a more permissive definition, but it does not include people not actively seeking a job but who want one and are available to start, still less hidden unemployment (ILO, n.d.).

The nature of the problem is compounded when we consider that unemployment is not a social risk covered by the social security system in most countries of the world. Dixon (1995) showed that 60 per cent of countries did not cover unemployment at all, and the rich countries of Europe and Asia (including the former Soviet countries) and America (USA and Canada plus 12 Latin American countries) formed the preponderant share of the 40 per cent of countries that did cover it. The picture has hardly changed since then. Only just over a fifth (21.8 per cent) of unemployed workers actually receive unemployment benefits. This leaves 152 million unemployed workers without social protection, most of whom live in poorer countries in Asia-Pacific, the Americas and Africa (ILO, 2017a). This global divide means that although unemployment no longer leads inevitably to unacceptable levels of hardship and poverty in a small number of countries, the majority of the world's working-age population in general and its unemployed people in particular are outside such provision as is made by their country's social security system - and thus also for all practical purposes from official unemployment itself (Van Ginneken, 1999).

This brief foray into some issues in delineating unemployment starts to illuminate the considerable divergence in what unemployment means as well as where and how it is manifested. The relationship to work, employment, joblessness, and thus also of poverty, needs to be understood as an entirely different dynamic for the majority of the world's unemployed than for the minority in the world that commands the overwhelming share of research attention. This is a social division that, broadly speaking, falls on a Global North-South axis. In many ways, the economic structures of the latter are so structurally different from those of the former as to render defunct the idea that there is a single universally applicable meaning of unemployment. Worldwide, waged jobs in the formal economy are the exception rather than the rule. Most countries have a very large informal economy that absorbs the vast number of people for whom there is no formal waged work and who are pursuing their own livelihood strategies, mostly as self-employed in the service sector or, for those in rural areas, in agriculture. In the absence of social safety-nets, people have to work one way or another. As Fox et al. (2016: i3) cogently state in relation to low- and middle-income countries of sub-Saharan Africa (SSA), 'unemployment is not high as it is considered a "luxury"'. They elaborate this statement thus:

$[\mathrm{M}]$ ost working age people in SSA cannot afford to be unemployed. Many families cannot fully support a recent graduate while he or she looks for a job, and many youth did not graduate from secondary school so would not qualify for a formal job anyway ... They will have to make their own livelihood, either by getting some land and farming, or starting a non-farm business. (p. i7) 
In essence, the informal sector absorbs most unemployment, which becomes hidden or disguised because unemployed people have to work to survive, even though they do not have a stable wage-paying job. The problem of unemployment thus reappears as marginal employment (often referred to as marginal attachment to the labour force), underemployment and, above all, in-work poverty where people cannot find enough sufficiently paid work to sustain them. Fox et al. (2016) illustrate this key point thus:

In low-income African countries, less than $20 \%$ of employment is in a wage-paying job, and about half of that wage employment is casual or temporary ... A more common situation in Africa is full-time employment but low earnings (often with high income variability), and widespread underemployment (not being able to work as many hours as desired, either in wage or self-employment) especially in rural areas. (p. i9)

The absorptive qualities of the informal sector together with the larger share of the economy that this sector occupies in lower-income countries means that unemployment headcounts cannot be taken as wholly reliable indicators of the 'health' of the labour market, household income, or of the wider economy more generally. It is also clear that although unemployment is inseparable from underemployment and informality, this inseparability is not unique to the informal sector. Thus, informal employment is also increasingly found in enterprises in the formal sector, in the form of 'atypical' employment such as 'clandestine employment, involuntary part-time work, work on short-term contract or no contracts, casual work', as well as 'labour on call' (ILO, 1993: 13-14, cited in Benanav, 2019: 124). The growth of such jobs reflects a process of casualisation and 'social dumping' whereby deregulatory measures create a pool of poorly paid and insecure urban workers that employers can use to replace many of the better paid, well-protected workers whom they employed (Benanav, 2019: 124). Casualisation goes hand in hand with falling numbers of official unemployment, further disguising the 'true' level of unemployment. This is because the terms of these jobs are such that unemployment is highly unlikely to be included as a coverable social security risk. (Indeed, the point of deregulation is to reduce employers' costs - or 'taxes' on jobs, as they might call them - and increase their power to set the working conditions of their labour force.) Equally, working in any capacity at any point in a reference period (primarily forms of underemployment such as short hours in multiple small jobs, or 'gigs'), disqualifies jobless people from being classed as unemployed. ${ }^{4}$

Young people are generally not eligible to be unemployed. Even in countries that in principle cover unemployment as a social risk, they mostly fail to pay the requisite number of contributions to insurance-based unemployment benefit schemes within the given amount of time. This does not prevent them from signing on, but there is little incentive to do so if they are not eligible for benefit payment. Also, many countries have instituted measures to divert young people from unemployment, either by assisting them into a job or removing them from the ranks of the economically active and thus also the potential to end up as openly unemployed. Examples include lengthening the period of compulsory schooling, expanding further and/or higher education and vocational training schemes, extending periods of skills development,

4 For this reason supplementary measures of labour under-utilisation, such as time-related underemployment and the potential labour force, and associated concepts of available and unavailable jobseekers, are sometimes used as indicators (ILO, n.d.). 
and instituting employment and business start-up schemes for young jobless people. Because of these measures, young people of working age feature disproportionately in the working-age economically inactive population than their share of the population would suggest. This point holds for nearly all countries, irrespective of income-level, with the exception of poorest (low income) countries that lack comprehensive post-compulsory education or welfare provision.

Education and class are major factors affecting the social composition and rate of YU. Studies of YU rates in countries that provide very little or no unemployment protection for under-25-year-olds typically find that YU tends to be higher amongst better educated groups (especially young graduates) but low amongst those with little or no education. The availability of family (financial) support to young people unable to secure or maintain a job is a key factor here. Godfrey's (2003) extensive study shows that in some lower middle-income countries (LMICs) (for example Cambodia, Egypt, Indonesia, Pakistan and Sri Lanka), historically, graduates have relied on the support of their relatively affluent families to maintain them during periods of prolonged initial job search for professional employment, while young people without any schooling or qualifications became vulnerably employed workers within the family (or nominally 'own-account' or casual workers when opportunities arose). The financial pressure for a young person to engage in job search, actually take a job and keep it is offset in cases where family support through intra-familial (informal) cash transfers is forthcoming. This is confirmed by Fox et al. (2016: i7) in relation to low-income countries (LICs) and LMICs in SSA:

Hidden in the low overall youth unemployment rate in low-income countries is a high unemployment rate among urban graduates. It is no coincidence that these graduates primarily come from the top end of the income distribution; only richer parents can afford to support youth in an extensive job search.

They cite the example of Mozambique, a LIC, half of whose population is classified as extremely poor. Here, although rural YU is 'almost non-existent' (at 1.7 per cent), in urban areas, as much as 20 per cent of young people are unemployed. Education is a predictor of this risk of unemployment: '[t]hose with secondary education and above are way over-represented in the unemployed group. Two-thirds of all urban unemployed reported that they had been in this status for over 1 year' (p. i7). This relationship between unemployment and education applies in higher-income SSA countries where broader social protection systems than those in LMICs or LICs exist. South Africa, an upper middle-income country (UMIC), for example, has a high official rate of YU, which (in 2014) stood at 42 per cent of 15-29-year-olds compared with 25 per cent of the working-age population (Bhorat et al., 2016; Fox et al., 2016: i7). In high-income countries, extensive schemes for unemployed workers that provide temporary financial support and help prevent unemployed workers from slipping into informality (ILO, 2017b: 40) do not obviate class-based social inequalities in the likelihood of entering unemployment - whether in its open or disguised forms. The availability of family support is a key explanatory factor in this.

These insights may well contribute to why the principal difference between the proportion of the 15-24-year-old population who are recorded as being unemployed across all country 
income groups (CIGs) is that, against reasonable expectation, YU is lowest by far in LICs. ${ }^{5}$ But it cannot be assumed that this is universally applicable across LICs and LMICs. ${ }^{6}$ Leaving aside the well-educated respondents in Godfrey's (2003) study of LMICs who declare themselves to be formally unemployed, the opportunities for other young people in LICs to find 'vulnerable employment' (typically one-off, seasonal or 'gig economy' work) beyond or within the household might be expected to be more limited. In practice, though, in LICs, 43 per cent are vulnerably employed, compared to 15 per cent in LMICs. This major difference is clearly reflected in the relative proportions of young people who are economically inactive: 43 per cent in LICs versus 66 per cent in LMICs. One interpretation of these data is that young people's opportunities to survive while being economically inactive in LMICs (and in many UMICs and high-income countries (HICs)) are far greater than those of their counterparts in LICs. However, reliable data on how the young people survive in these latter countries in the absence of state-provided social protection are extremely sparse.

Such complexities are amplified for young people because they are at the outset of their working life when education and family support combined with other measures to divert them from registered unemployment feature strongly. Despite its limitations, unemployment is a well-known concept that commands a great deal of attention internationally. It remains the most commonly used indicator of the 'health' of labour markets and economies that, for all its flaws, is widely respected. It is also capable of visibilising harms generated by labour systems and mobilising wider action for economic and social justice in ways that no alternative concept can. Used sensitively, with caution and specificity, informed by an appreciation of the qualifiers we have briefly outlined and how they shape the overall prevalence, social composition and structure of unemployment, the concept remains a powerful one. We are, in sum, confident that unemployment is a productive analytical category, providing that an expansive definition of it is used - one that recognises, first, the inseparability of unemployment, underemployment and informality as structural characteristics of labour systems internationally, and, second, the intersecting familial, educational, welfare, and labour domains that produce the worlds of work and welfare in which young people are embedded.

\subsection{ENDEMIC UNEMPLOYMENT: DEFINING THE CATEGORY}

We deploy the term 'endemic' in the concept of EYU as a defining generic category of (youth) unemployment. This is to avoid the complexity of multiple versions of unemployment used by labour economists and others, and to differentiate our approach in order to provide greater clarity about some of the key characteristics of YU with which this book is concerned. Economists differentiate primarily between frictional unemployment, structural unemployment (sometimes called technological unemployment), cyclical unemployment, systemic unemployment and political unemployment. Structural, systemic and political unemployment are of most relevance here. Structural/technological unemployment is typically defined in

\footnotetext{
5 The respective proportions of young people who are wage workers, vulnerably employed and economically inactive vary hugely between country income groups. But despite these differences and the vast gulf between those countries, the proportions of young people recorded as unemployed actually vary remarkably little: 5 per cent (LMICs) and 9 per cent (UMICs): see Chapters 3 and 5.

6 Godfrey et al. (2003) point out that YU is weaker in Latin American countries, and is inverted in 'transition' countries - typically Eastern Europe and Central Asia.
} 
terms of unemployment that arises because of a decline in demand for the goods or services produced by firms or organisations; or because labour-saving technologies that are more economically productive, efficient and/or profitable enable firms and organisations to reduce the size of their workforces. Political unemployment is unemployment deemed to be the result of interjections in the predominant organisation of production and labour on the part of powerful interest groups, organisations and governments that seek to alter the structures or processes of employment for their own advantage or the advantage of those whom they represent or are governed by. The most widely recognised and used categories of political unemployment are protectionism (typically as exercised by trades unions) and labour flexibilism (typically on the part of managers, owners, investors or of capital itself). One of the purposes and effects of interventions by the former group is to prioritise securing members' job security, while those of the latter group are to maximise profits accruing to owners, etc. Systemic unemployment is 'allowed' to accumulate when convenient, such that a fraction of the total labour force is normally reliably without work and waiting to be employed - either available to start work if there is an increase in demand for goods and services, or accustomed to their status as unemployed when they are no longer needed if demand falls. 'Full employment' and minimal frictional unemployment are relatively rare, at least at national levels. On one interpretation, systemic unemployment provides a reliable, flexibly available 'reserve army of labour' (RAoL) a concept we revisit in Chapter 3 in particular.

YU 'at scale' is typically primarily the product of one or more of these categories of unemployment at any time or place, assuming young people are ready and able to take up the jobs on offer. Historically, much large-scale YU has been explained using theories associated with the concept of cyclical unemployment. In free-market capitalist economies, the 'business cycles' of any country are liable to peaks and troughs related to the confidence consumers and service-users have in the state of the economy, to what they believe their money buys now and in the near future, and to consequent fluctuations in demand and in supply at prices that are acceptable to all parties directly or indirectly involved in financial transactions.

Our argument is that structural unemployment and cyclical unemployment alone no longer provide adequate explanations for the nature of YU or for trends in YU globally. The GFC - like the Great Depression of the early 1930s - was undoubtedly an example of (almost worldwide) instability in financial markets that resulted in an extreme form of cyclical unemployment, combined with the key characteristics of structural unemployment (Tooze, 2018). But, as Chapter 5 will show, the scale of YU had already been much greater than that of adult unemployment for several decades before the GFC (sometimes at extreme levels in some countries like the UK in the 1980s and 1990s, for example), and continued to be so, long after adult unemployment rates had recovered in all but the very worst-affected countries.

To capture this, we deploy the term EYU to convey a fundamentally different set of meanings about the nature and causes of YU worldwide from those that are normally used. Although the concept 'endemic' has its origins in epidemiology regarding the spread of disease following epidemic trajectories, our use of the adjective endemic is intended to encapsulate a social meaning of prevalence, persistence and permanence. As a social science concept, it conveys the sense of a harmful phenomenon that spreads across borders and barriers, does not 'naturally' die out, but is reproduced, sustained and endures over time, with no reliable or anticipated end-point. EYU is the product of failures whether on the part of governments, warring armies, criminals, fraudsters or - as we shall argue - institutions of global governance 
to intervene to prevent the privations, extremes of poverty and reduced life-expectancy associated with extended and unrelieved periods of unemployment.

Adopting the terminology of EYU circumnavigates alternative terminology that is inherently imprecise, unsatisfactory or unreliable as a way of conveying the seriousness of the nature of EYU. In many cases and at certain junctures, the scale and volume of YU might seem to warrant the term 'mass unemployment' - a term which was historically only widely deployed in public discourse and academic literature after the Great Depression of the 1930s. We have generally avoided using this term unless essential, in part because it is inherently ephemeral in terms of the conditions it captures, but especially because it overlooks persistence over time as a crucial characteristic of many instances of unemployment that are distinctively harmful without ever receiving attention of the kind that is reserved for 'global emergencies' like the Great Depression and the GFC. Put simply, EYU recognises that duration is at least as important as scale in many contexts.

\subsection{INSCRIBING 'THE GLOBAL’ INTO ENDEMIC YOUTH UNEMPLOYMENT}

The long shadows cast by the GFC and its political management have been a source of renewed interest in ongoing processes of the globalisation of social and economic policy and transformations of the global social system. The last decade has seen a resurgence of critical scrutiny of how international banking and finance have been governed and regulated, not just by domestic institutions but by global ones, and of how international organisations (IOs) have responded to the social and economic fall-out of the GFC (Schoenbaum, 2012; Tooze, 2018). This particular financial crisis reinforced like no other the salience of global macro-analytics and of attending to the structural features of capital accumulation and the institutions of global governance. Comprehending this crisis, its origins, unfolding, and aftermaths, has required not just a country-scale analysis but a truly global one capable of understanding how the crisis spread rapidly across multiple countries, regions and continents of the world, drawing in ever-wider areas of public policy and numbers of people affected. Connecting this global dynamism with the micro-worlds of everyday lived experience was given new impetus, particularly when the impacts of ensuing programmes of economic austerity and welfare restructuring were taken into account. These analytical threads provided insight into the sources of social conflict that pre-existed the GFC but which were aggravated and intensified by it. Fuelling insurgencies of many kinds, and fragmenting the international order that had governed the world economy for more than half a century, by some accounts the GFC marked the beginning of a new dynamic of 'de-globalisation' (Livesey, 2018; see also van Bergeijk, 2017).

Remarkably few of the tenets of such powerful analyses of the global system as have (re) emerged during this time have been tested in the realm of YU. Global restructuring remains, it seems, merely a remote, abstract feature of the contemporary social, economic and political conditions shaping young people's labour market experiences, if we are to go by the preoccupations of youth studies in recent years, that is. Although analyses of country-specific YU data abound, YU is still seen as primarily national in its causes and effects; that is, the analytical focus lies with domestic institutions, domestic spheres of governance and domestic policy actors conditioning intra-national processes. Furthermore, since 2008 there has been a pro- 
liferation of (mainly economics-led) academic literature on YU, a much sparser sociological and political-economic literature, and a notable dearth of social policy literature (almost all in the form of papers in reputable social science peer-reviewed journals or from international governmental organisations (IGOs)). Dominating these debates, consequently, is a focus on formal labour markets and training, education and employment policy sectors. Analysis of YU as an expansive social policy issue has attracted remarkably little coherent attention.

One problem is that the analytical paradigms used in the study of YU globally remain firmly rooted in the methodologically 'thinnest' sense of 'global', equating it with 'worldwide'. And even this turns out to be much less than genuinely globe-spanning. For example, Peter Blossfeld et al.'s (2008) otherwise majestic comparative study of eleven 'modern societies' (their term), Young Workers, Globalisation and the Labor Market was restricted to some European countries plus the USA. Despite invoking globalisation, it was posited as contextual, in the background vaguely somewhere, but in no way taken up through investigation of how different sorts of globalising structures actively condition youth labour markets or the quality of youth employment. Undoubtedly, forensic studies of young people's encounters with employment pathways are important, but on the question of how globalisation processes tangibly impact on these, Blossfeld et al. obscure more than they reveal.

In similar vein, Alan France's (2016) study, entitled Understanding Youth in the Global Economic Crisis, had a great deal to commend it as a response from youth sociology to the GFC, but the depth and breadth of its analysis of mass YU offered is also peculiarly narrow. Its claim to international coverage in the context of a global financial crisis is limited. Its geographical coverage is highly selective, covering the UK, the British Commonwealth of the (affluent) 'Global North' (Canada, Australia, New Zealand), three European countries (Spain, Norway, Poland) and Japan. Like Blossfeld et al., France's invocation of 'global' obscures rather than reveals transnational modes of production and governance of youth (un) employment.

Most recently, The Crisis of Global Youth Unemployment by Tamar Mayer, Sujata Moorti and Jamie K. McCallum (2019), with especially its interesting opening chapter on global labourscapes (cf. Appadurai, 1990) intended to convey 'the variegated effects of youth unemployment, including the new cultural and political formations that [revolve around precarity] have come into being as a result' (p. 2), turns out to be a fairly conventional international study of YU, albeit one that extends its gaze to a commendably wider range of development contexts than those usually covered by such volumes. Unusually, it includes countries from the Global South - China, Pakistan, South Africa, and 15 countries comprising West Africa - as well as those from the Global North. Still, with the exception of the West African contribution (Bergson et al., 2019), the youth 'labourscapes' that the volume depicts are all too familiarly constructed around 'container' notions of the nation state. Only Bergson et al.'s chapter approaches a sense that transnational sites of political engagement and action, in the form of global and sub-global institutions such as the Economic Community of West African States (ECOWAS), EU, World Bank (WB) and International Monetary Fund (IMF), have any bearing on the (re)making of 'global youth labourscapes'. Beyond that, the ostensibly-central notion of 'global society' referenced in the introductory chapter is taken up by none of the later chapters.

These books and others from the social science canon from which they emanate pay scant serious attention to globalising dynamics of YU. Indeed, almost all of the ostensibly relevant 
sociological volumes since 2008 are indicative of an entrenched methodological nationalism combined with advanced country bias that result in insufficient attention to: the extensive international scale of YU, including outside high-income development contexts where the majority of the world's youth labour force and young unemployed people reside; the implications of greater international interconnectedness and interdependence for how institutions of work and welfare for young people are organised, and how these bear upon YU; and the ways in which YU has been taken up as a policy issue within cross-border spheres of governance together with the forms that global institutions' interventions take and their impacts on the course of national policy-making or on domestic economic and social structures.

The omission of globalist narratives in studies of YU is surprising. It is now well-established that a major characteristic of contemporary world history is the intensification and expansion of capitalism on a global scale, and that employment structures are shaped by global forces (Dicken, 2009, 2011; O'Brien, 2014). Just as global analytics of the world economy is understood as necessary to grasp the structure of employment, so too this point applies to unemployment. As Benanav (2014), a historian, argued, unemployment is a 'story' that actively requires 'the global' be fully integrated into any modern history of it. This is because the worldwide expansion of unemployment since 1950 .

... was in large part the result of processes that unfolded at the global level: first, a massive increase in the world's population, and in particular, its working population; second, a global 'Green Revolution,' which significantly reduced the price of food, but also resulted in a worldwide wave of agricultural exit; and third, a global wave of deindustrialization, which unfolded not only in the high-income countries, as is well known, but also, across the low-income world. The result was a huge increase in the global supply of labor, relative to a weak demand, and that in turn created a gigantic population of unemployed people .... (p. 6)

This does not deny the complexities and variations in where and how these processes have unfolded, including how they 'touch down' in historically and geographically context-specific ways. However, powerful social forces such as these are essential to understanding who gets which jobs and who is excluded from a job, why, how, under what conditions and with what effects, outcomes and impacts (ILO, 2016). How global restructuring distributes benefits, risks and costs is, we argue, conditioned by international institutions and policies and not just national ones. Indeed, international institutions have been active agents in the (re)making of unemployment. Benanav's study of half a century of ILO involvement in the making of such labour market realities shows this all too well (Benanav, 2019).

Young people and YU have been largely invisible from academic theoretical or empirical literatures on global economic restructuring. Social divisions and fractures of class and gender shaping the course, timing and outcomes of contemporary 'globalisations' and the (re)making of contemporary capitalisms are, relatively speaking, well-trodden paths compared with those of age. The voluminous literature on global labour, corporate restructuring and international institutions contains next to no dedicated attention to how they re-position young people's labour. As a result, we know less than we should by now about the 'youth' dimension of unfolding global economic processes and their impacts on structures of unemployment on a world scale. Yet there have long been clues that there is a distinct youth story to be told. For example, long before the GFC, youth labour markets worldwide had begun to change significantly, and in some sectors radically, as a result of North Atlantic neo-liberal globalisation and 
the restructuring of many labour markets that it brought about. In turn, much of the change in youth labour markets (YLMs) is a particular version of labour market transformation to which the contexts and conditions of YLMs were amenable. This is just one example to illustrate the general point. As will become increasingly evident throughout this book, the ostensibly fluid, adaptive, absorbent attributes of young people and the YLMs in which they are embedded represent a mix of qualities that are apparently well-suited to the very forms of the labour flexibilisation upon which labour markets transformed by neo-liberal globalisations both depend and also help to foster.

Our inscription of young people into these 'global labour shifts' (cf. Dicken, 2009) is cognisant of the structural differentiation of both capital and labour and how they remain embedded in socio-institutional contexts that vary across time and place (Silver, 2003; Hardy et al., 2016). Cognisance of this differentiation is vital when it comes to young people because, as we will show, they are distinctly placed within labour forces. Not only are they the most likely of all age groups to be jobless, but those with jobs are more likely to be in 'precarious' forms of employment in 'disorganised' workforces - whether because they have eschewed collective forms of action or because they are prohibited by law and policy from forming or joining labour unions. Irrespective of how we label this (for example, 'surplus labour', 'global youth reserve army', 'flexible labour force'), the underlying dynamics of social organisation that position young people in this way is not well enough understood.

\subsection{AIMS, SCOPE AND DIALOGIC TERRAINS}

As we hope will be clear by now, the premise of this book is that $\mathrm{YU}$ is best understood as a global phenomenon necessitating broad-based social policy analysis. The nature of global $\mathrm{YU}$, we argue, is such that it can only be understood by reference to global(ising) processes unfolding over time across the interlinked spheres of economic organisation, labour systems and social policies. Our commitment to a transnational analytics is driven by a deep frustration with the lack of scrutiny of the relationship between YU and macro-level conditions of development in general, and with the shifting social foundations of capitalism more specifically. This frustration with the lack of such a perspective has grown during our ongoing collaboration over the last decade to monitor and analyse evolving global policy on YU (Fergusson and Yeates, 2012, 2013, 2014; Fergusson, 2016a, 2016b, 2017, 2021). That work highlighted to us the need now more than ever for an extended project capable of bringing to bear a new way of looking at the production and governance of EYU as a global phenomenon. That extended project is this book.

At the same time, we are of course cognisant that no single study can make good all these limitations or come close to doing full justice to the many complexities of YU as a social policy field - global or otherwise. Many important facets of the causes, nature and effects of global YU are beyond the scope of this study. Prioritising an analysis through the lens of social policy limits the scope to do justice to some sociological and most psychological paradigms, for example - a point on which we expand briefly below. We have not attempted to pay more than passing attention to many important adverse 'multiplier effects' of being young and unemployed (or unskilled and poor) - not only for individuals but for the lost societal and economic benefits of engagement in paid work and its associated socially integrative effects. Relatedly, questions of how young people's interests are represented inside the workplace, and 
especially when they are excluded from it, deserve consideration that we do not have space to pursue. The voluminous migration of young people across national and continental borders is now deeply inherent in regional (mal)distributions of (un)employment, and are deserving of a parallel comprehensive global study in their own right: disconnected glimpses into this domain are at serious risk of masking much more than they reveal in terms of understanding the global dynamics of YU. The final chapter of the book makes a challenging and radical suggestion as to how IOs might lead a set of major interventions that would address endemic YU at a genuinely global scale, but space and the need to maintain focus and coherence have otherwise prevented us from considering national or localised policy-driven solutions to YU.

Partly in recognition of these caveats, we limit the book to five principal aims. These are to:

1. Identify the salience of EYU as a major social policy issue of global significance;

2. Elaborate a transnational analytics of global EYU;

3. Scrutinise how global EYU is manifested across diverse development contexts;

4. Examine how global EYU is responded to by transnational social actors, institutions, and policies;

5. Consider the implications of our analytical findings for research and policy.

Breaking down these broad aims into specific objectives, these are to:

1. Highlight inequalities and social and economic injustices of age and gender amongst young people worldwide (expressed as the likely immanent failure to meet or substantially progress SDGs 8.5 and 8.6);

2. Advance understanding of the diverse manifestations and persistent underlying causes of EYU, at scale;

3. Extend analysis of the institutional architectures and functioning of transnational policy, as seen through how YU is taken up and responded to by international actors in spheres of cross-border governance.

Based on rigorous original analysis and research, and bringing new, robust evidence to light for the first time, we offer the first sustained major academic social policy research study into global YU as an endemic and universal feature of contemporary social organisation worldwide. We argue that YU is a global phenomenon that requires multi-disciplinary theoretical and empirical social policy research. We add our voices to those of many colleagues who are already convinced that it is not meaningful to research and analyse the contemporary organisation of labour and welfare solely in terms of domestic economies, institutions, governance and policy. And we hope to persuade others of the merits of a transnational analytics in relation to this issue and others. To both, we offer some ways of thinking about how our study can enhance efforts to understand the causes of YU and the array of responses to it, and how future research might take forward this study through further research.

As such, this book aims to contribute to ongoing assessments of the condition of labour and the state of welfare within the contemporary world order. From Chapter 2 onwards, it 'speaks' to debates about the sources and growth of social inequalities, the effectiveness of responses to their causes and consequences, and key social policy issues and priorities in the light of the SDGs. Within this, three principal dialogic terrains structure our discussion. These are outlined below. 


\subsubsection{Global Economic Restructuring and Endemic Youth Unemployment}

The first terrain concerns how populations, welfare systems and economies are differentially embroiled in globalisation processes and their wider social and developmental impacts. Key debates revolve around the global economic dynamics of inclusion and exclusion, and the extent to which the terms of international integration have brought net gains to previously marginalised economies and labour forces or whether they have accentuated inequalities and undermined socially sustainable forms of economic growth and development. Are these transnationalising dynamics indelibly and universally bound to a trajectory of widening and deepening socio-economic insecurity? Or is a more complex narrative warranted - one that recognises multiplicity and complexity, and which entertains the possibility of parallel and contradictory forces at work simultaneously?

Principal questions centre on the implications for employment and jobs - who accesses them, where, and on what terms (Munck, 2002; ILO, 2016)? Unemployment as one form of labour market exclusion has featured as a barometer of the 'new' global dynamics of exclusion and inequality, but remarkably few studies evidence a dedicated and sustained focus on young adults. By examining these processes through the prism of $\mathrm{YU}$, we aim to provide important new evidence about the global restructuring of labour markets and labour systems, together with the specific forms that inclusion/exclusion and inequality take. Some have suggested that young people's labour market position is actually improved as a result of economic globalisation (de Lange et al., 2014). However, the strength of accompanying evidence about how globalising economic dynamics restructure labour markets and the implications for the quality of jobs within the rich countries is unclear. There is even less clarity about this in relation to the poorer countries. In this context, we scrutinise whether such dynamics re-position young people in labour markets: do 'new' sorts of differentiation and inequality emerge in this process and are existing ones mitigated or dissolved? What are the 'new' social edifices being built that help interpret the production, distribution and composition of EYU, globally? These debates and questions are the focus of Chapters 3 and 4.

\subsubsection{The Global Financial Crisis and Endemic Youth Unemployment}

The second terrain concerns the impacts of the GFC on EYU. The GFC that began in 2008 and the consequential Eurozone crisis $(\mathrm{EzC})$ that erupted in its wake combined to raise international awareness of the scale and impact of economic and financial failures on young people's lives and prospects. Triggering echoes of the global economic depressions of the early 1920s and 1930s and the poverty, suffering and unrest caused by mass unemployment, the GFC and EzC brought to public and political attention the effects of unemployment that were persistent and in many contexts endemic. Of particular concern was the extent to which the effects of these crises fell especially heavily on young people - initially school leavers, then progressively those up to and beyond the age of 25 years - and persisted in some world regions and countries long after the most immediate financial and economic effects of crisis had been ameliorated (Verick, 2009; Bell and Blanchflower, 2010, 2011; Scarpetta et al., 2010; Choudhry et al., 2012). The overarching sources of debate and contention concerned why young people were so badly affected over such an extended period as to become popularly labelled as 'generation jobless' in the Global North (Dorling, 2013; Vogel, 2015); why mass YU remained persistent 
(Bruno et al., 2014; Caporale and Gil-Alana, 2014); and why the geographies of the scale and persistence of YU were so variable (O’Higgins, 2012; Mai, 2014).

Beneath these debates lie more fundamental questions and concerns that remain largely unanswered. Was the GFC unprecedented in its effects on the scale and persistence of YU, or was it so internationally notable because of its acute impact on high-income countries? Prior to the GFC and since the Second World War, has the partial recovery from the GFC in the Global North largely allayed the threat of EYU at scale, and if so how far has it done so by transforming the norms, policies and conditions of youth labour markets? Were the scale and profiles of mass YU that followed the GFC exceptional only in the context of the Global North, and are they entrenched characteristics of youth labour markets in many countries of the Global South? These debates and questions are the focus of Chapters 5 and 6.

\subsubsection{Global Governance and Endemic Youth Unemployment}

The third terrain concerns processes of global social governance and policy formation. Transnational actors, such as IOs, occupy a key place in these, not only because they are, for some, an expression of the apparent erosion of state sovereignty in a globalising world, but also because they are major participants in processes of 'changing norms about the legitimate role of the state in the economy and in the provision of security' (Biersteker, 1992: 104, 2013; Weiss and Wilkinson, 2014). It is by now well understood that socio-economic security and social policy are an essential dimension of this (re)configuration of norms and that IOs are meaningful social policy actors therein. IO programmes of global social regulation, redistribution and rights influence domestic policy content and outcomes, and individual and collective welfare worldwide (Biersteker, 1992; Deacon et al., 1997; Yeates, 1999, 2002, 2007, 2014; Lee et al., 2002; Orenstein, 2008; Jakobi, 2009; Kaasch and Martens, 2015; Martens et al., 2020; Yeates and Holden, forthcoming).

A great number of studies now abound of IOs and other transnational social actors in processes of global social problem construction and global policy formation. These variously address the processes by which social issues become defined as ones of immense importance to global society and as matters for global social policy, the forms that global social policies take, and the contexts, sources of legitimacy and mechanisms that enable IOs to become and remain meaningful and influential actors in shaping global social welfare outcomes (Yeates and Holden, forthcoming). Knowledge of global social policy formation in relation to different policy sectors and issues has developed significantly in recent years, but not in relation to young people or on matters of unemployment, with the exception of our own contributions. ${ }^{7}$ How is YU viewed and addressed in this context? Is it an exclusively economic issue or one that is the sole prerogative of country-level action, or is understood as a social and political issue that has consequences beyond nation states and as a matter for collective action on an international scale and a subject of action led by institutions of global governance? What powers do IGOs have to address YU, and how have they exercised them? How have organisational values and cultures translated into priorities for action, and what kinds of action have they instituted? How have IGOs collaborated with one another, and with what results? How successful have they been in terms of influencing collective action? By charting how YU has

7 See Fergusson and Yeates, 2012, 2013, 2014; Fergusson, 2016a, 2016b, 2017, 2021. 
come to be defined as an ongoing matter for global social governance and policy over the course of a century, and with what effects, our study helps locate EYU within a global institutional field of policy and action that is an integral part of the contemporary global social organisation of work and welfare. These debates and questions are the focus of Chapters 7 and 8 .

\subsection{VALUES, METHODS AND EVIDENCE}

The normative standpoint of this research is that the extent, prevalence and apparent permanence of high levels of YU are a matter of social and economic injustice. Extended periods of YU reflect wider social inequalities and exacerbate them, inflicting long-term individual and societal harms. EYU contravenes international norms and goals, and tackling it is a priority of the first order in socio-political projects aiming for egalitarian, inclusive and cohesive social structures.

Epistemologically, we adopt a nomothetic approach to the nature of relevant knowledge in this field and to our methods of data collection and analysis. In practical terms, this means we focus on prevailing trends, general tendencies, and generalisable propositions perceived through broadly based surveys and analyses of material conditions, social and economic structures, political processes and their priorities and loci and distributions of power. ${ }^{8}$ In the context of this study, we have limited interest in the personal experiences, psychological characteristics or behaviours of young people who are most harshly affected by YU - not because these considerations are unimportant, insubstantial or resistant to social science analysis, but because the scale and scope of our study places such considerations beyond what can be encompassed here. Our evidence base is comprised entirely of policy sources and statistical and qualitative data. Our research did not involve human participants. Our data and the four datasets we constructed are described below.

\subsubsection{Quantitative Surveys of Worldwide Youth Unemployment Trends and Dynamics}

We undertake quantitative analyses of worldwide YU based on three datasets constructed for this study. The datasets are derived from publicly available data and help analyse YU rates or trends at the level of countries and/or groups of countries.

The first dataset collates key aspects of youth labour data from the ILO's statistical database, ILOStat. It collates the total cumulative employment status of all 15-24-year-olds in all countries for which such data are available. This amounts to data on 757 million young people across 142 countries and territories. We use this descriptively in Chapter 3 to better understand how YU is distributed worldwide and its compositional basis. We group the data according to four categories: wage workers, vulnerably employed, unemployed and economically inactive. We further group it according to the standard WB country income groups: high income,

8 This approach is perhaps most readily understood in contradistinction to idiographic methods and analyses that prioritise foci on specific cases, events or individuals, their personal understandings and expressed meanings, their 'lifeworlds' and their constitution as unique entities, and the specific instances and effects of their actions. 
upper-middle income, lower-middle income and low income. Further information about the dataset, its scope and limitations, is provided in Section 3.3 of Chapter 3.

In order to understand better how EYU is socially structured on a worldwide basis we turn to international datasets of the ILO, WB and United Nations Development Programme (UNDP). ILO and WB data are useful for describing broad trends in YU over time and their manifestation across diverse development contexts (Chapter 5), but in order to understand better the relationships between long-run YU rates and wider economic and social factors (Chapter 6) we constructed two further datasets. The first of these collates long-run aggregated YU rates and GDP between 1980 and 2018 for 74 countries. It enables further exploration of the relationship between annual changes in whole-population YU rates and annual changes in economic growth, country by country, on a worldwide basis. It also facilitates comparison with a validated relationship of correspondence between degrees of change in terms of changes in total unemployment rates across all age ranges and changes in GDP, as postulated by Okun's Law. Our dataset and findings from it greatly extend preliminary assessments of the relationship between changes in GDP and YU by focusing exclusively on young unemployed people and for a far wider range of countries worldwide and over longer periods (Chapter 6). A second dataset cross-tabulates the mean national YU rates of 73 countries for the period 1991-2017 against the mean national UN Human Development Index (HDI) rating for the same period. ${ }^{9}$ This representation of the standing of these countries facilitates a close reading of the relationship between the prevalence of long-term YU and human development factors that go beyond the state of the economy. The dataset enables us to differentiate this relationship by country income group. An important feature of both these datasets is that they enable us to test specific propositions regarding the impact of the GFC on YU on a worldwide basis.

All data used for these datasets have been extracted directly from ILO, UNDP and WB sources, using the most recent approved data available (mostly (up to) 2018/19). These data are publicly available open access data. Appendices 6.1, 6.2, 6.3 and 6.4 describe the data, present modelling methods and outputs, and provide data values. This enables readers to check and test our analyses. Some of the countries we wished to include in our analyses do not have complete data over the time periods of our analyses (and we note more generally that there are established and particular difficulties with sourcing accurate standardised data, for example in low-income countries and war and armed conflict zones: see Chapter 5 and Jerven, 2013). We made informed decisions as to the appropriate limits of using incomplete data of this kind, and recorded these decisions in footnotes at the relevant points in the text and in Appendices 6.1-6.4.

\subsubsection{Qualitative Survey of Global Youth Unemployment Policy}

A parallel study based on archival research and qualitative data relating to the history of global policy on EYU was carried out (Chapters 7 and 8, Appendices 7.1 and 8.1). We trace these responses from the beginning of the twentieth century when the ILO was established (1919) to 2020, by which time the organisational features of the policy field had developed

9 The HDI is a composite index for each country, calculated on the basis of the health and longevity of its population (life-expectancy index), its knowledgeability (education index), and its standard of living (gross national income (GNI)). 
considerably, in terms of the participants and their interactions, and the scope and range of their interventions.

Policy can be tracked through a range of genres (policy reports, official reports, political speeches, interviews, press releases, briefings and media reports), and the historical contours of most public policy action can usually be traced through these. We focused on official documents to trace the 'evidential fingerprints' of IOs' contributions to shaping the policy field over time. These included reports (annual, thematic or special/ad hoc reports), quasi-technical documents (for example, monitoring and evaluation guides for practitioners), Minutes, Notes, Resolutions and formal statements. We considered working papers and evaluation reports prepared by external consultants if they were published by the organisation, though they were assigned lesser weight than official documents of the organisation. All of the documents examined are publicly accessible. Each document is an individual piece of evidence that, taken by itself, has fairly low probative value, but cumulatively can strengthen evidence of a wider pattern or tendency within a sequence of interventions.

Our primary sources were the UN's libraries system, notably the Dag Hammarskjöld Library, the ILO Library (including its online database, Labordoc), the Library of the UN Office of Geneva (UNOG) which hosts the League of Nations Archive resources, UNICEF's Office of Research-Innocenti virtual library, and UNESCO's resource documentation (UNESDOC). We also consulted the e-libraries of the OECD, WB and IMF. Other website-sourced documentation from the UN and elsewhere helped construct the involvement of other international policy actors from the corporate and third sector in the policy field.

Our analytical aims were to identify the major organisational characteristics of the global policy field, its ideational, discursive, institutional, agentic and programmatic structures and the axes of alignment and divergence, cooperation and contestation underpinning them. Guided by process tracing methodology, we used a descriptive inference method to generate 'mechanistic' evidence about all these organisational aspects of the field. Such evidence is essential to delineating and probing previously unchartered policy terrains, though in and of itself the observations it gives rise to and the empirical record into which it feeds do not warrant causal inferences that can logically or robustly be linked to specific outcomes within the chosen case or comparatively with other cases (Beach, 2017; Collier, 2019). That said, our method proved more than adequate for our aim of systematically charting the principal organisational features of global YU policy. We did not seek to test causal relationships about why these actors responded as they did. In this, our method may be termed process tracing 'lite' (Beach, 2017).

Our analysis initiated search terms beginning with 'youth', 'youngster(s)', 'young people', 'unemployment', 'employment', 'labour' and 'work' to identify key documents and sift them for dominant cognate concepts used in the field. We repeated the document searches for concepts - for example, 'employment', 'underemployment', 'informal', 'informality', 'insecurity', 'precarity' and 'youth development' - either on a standalone basis or in combination with one another. We constructed a descriptive timeline of relevant events, milestones, organisational actors and programmes, by sifting documents. We looked for an evidential trace of different kinds of interventions, regarding institutional development and processes of policy formation, as well as of substantive matters of policy content. Each year was covered to construct the long-term timeline. We coded qualitative aspects of observed activity using manual techniques. We wanted to understand not just the frequency of activity, but also its 
nature - for example, whether the discursive intervention(s) was ephemeral (for example, a passing reference) or more substantial (for example, fully fledged analysis); whether the corresponding action (if any) was a one-off intervention or indication of a sustained presence. The volume of documentation we sifted was substantial. For example, the UN General Assembly's (UNGA) Resolutions database is a vast resource comprising nearly 20,000 entries. The annual proceedings of the International Labour Conference routinely run to over 300 pages each. Similar volumes of documentation exist for other organisations.

Conflict of interest declaration: The research was not financially supported, directly or indirectly, by any entity or organisation that is the subject of this study. We declare no conflict of interests that may cast doubt on the integrity of our research or its reliability.

\subsection{A NOTE ON TERMINOLOGY}

Unless otherwise stated, the default age range of our study is 15-24 years old. This range corresponds with the UN definition of youth and therefore provides the most stable and universally-applicable definition of youth. We recognise, however, that youth is a constructed, contested and ever-changing social category, as well as the fact that the de facto starting working age for young people in parts of the world is less than 15 years old (an age that the rich world would class as falling within the ambit of childhood). We take due account of this as far as is reasonably possible for a study of this kind.

Unemployment has multiple meanings and casual use of this term can be a major source of confusion as well as analytical bluntness. We therefore distinguish between 'open' or official unemployment and 'hidden' or 'disguised' unemployment. We preface which sort of unemployment we mean by using one of these terms, wherever appropriate. For maximum clarity, we also identify which measure of unemployment we are using. We reserve use of the term 'endemic' adjectivally and specifically to mean (youth) unemployment that is prevalent, persistent and permanent (see Section 1.3, p. 9 and Chapter 5).

We use the term 'international organisation' (IO) as an umbrella term to encompass international governmental organisations (IGOs) (for example, ILO, WB, IMF) and international non-governmental organisations (INGOs) (for example, International Trade Union Confederation). However, we use IGO or INGO as appropriate where we are deliberately referring to one rather than the other. The GFC and its effects are recurrent concepts throughout the book. We refer to 'pre-GFC' and 'GFC' periods but avoid reference to any 'post-GFC' period: there is no universally applicable definition or marker of when the GFC and its downstream effects 'ended' (or will 'end') in any given country or group of countries. Where unavoidable, the need for any such reference refers to periods following the peak of the GFC and/or its apparent peak effects.

The variety of terms used to portray and categorise the countries of the world is immense. None stands out as wholly or universally satisfactory. In this book, we restrict ourselves to two categorisations. The first is geographical place, in the sense of a region (for example, Western Europe, South America, Northern Africa, East Asia) or a continent of the world (Europe, America, Africa, etc.). Where we refer to politically constructed regional groupings of countries, such as the European Union, the Association of South-East Asian Nations (ASEAN) and so on, we term these world-regions (though the African Union is, strictly speaking, a continental grouping). The second categorisation is the delineation of countries in terms of 
their 'development' status, the most commonly used of which is the World Bank's four-fold classification of countries by income/GDP/GNI, and the UN's HDI which, in addition to GDP, also incorporates measures of education and health. We use both the WB and UN's country classifications. We permit ourselves the occasional foray into the language of 'rich' and 'poor' countries, and other terminologies (such as core, semi-periphery and periphery). We use the term capitalist and capitalism in a general sense, unless we expressly state we are using it in a more specific (Marxist or Marxian) sense. 